\title{
Source identification and health risk assessment of Persistent Organic Pollutants (POPs) in the topsoils of typical petrochemical industrial area in Beijing, China
}

\author{
Jun Li ${ }^{\mathrm{a}, \mathrm{b}}$, Yong Huang ${ }^{\mathrm{c}}$, Rong Ye ${ }^{\mathrm{a}, *}$, Guo-Li Yuan ${ }^{\mathrm{a}, \mathrm{b}, * *}$, Han-Zhi Wu ${ }^{\mathrm{a}}$, Peng Han ${ }^{\mathrm{a}}$, Shan Fu ${ }^{\mathrm{d}}$ \\ a State Key Laboratory of Biogeology and Environmental Geology, China University of Geosciences, Beijing 100083, China \\ b School of Earth Sciences and Resources, China University of Geosciences, Beijing 100083, China \\ c Beijing Institute of Geo-exploration Technology, Beijing 102218, China \\ d State Key Laboratory of Environmental Chemistry and Ecotoxicology, Research Center for Eco-Environmental Sciences, Chinese Academy of Sciences, Beijing 100085, China
}

\section{A R T I C L E I N F O}

\section{Article history:}

Received 27 August 2014

Revised 16 April 2015

Accepted 24 July 2015

Available online 29 July 2015

\section{Keywords:}

Persistent Organic Pollutants

Petrochemical industrial area

Beijing, China

Source identification

Risk assessment

\begin{abstract}
A B S T R A C T
Thirty-one topsoil samples were collected from the area of the Yanshan petrochemical industries to comprehensively determine the spatial distribution, the possible sources and the potential risks of legacy Persistent Organic Pollutants (POPs) in a typical petrochemical industrial area. The total concentration of 16 PAHs, predominantly originated from the local emission from fuel combustion, ranged from 35.29 to $6120.22 \mathrm{ng} / \mathrm{g}$ with a mean value of $906.11 \mathrm{ng} / \mathrm{g}$. Organochlorine Pesticides (OCPs) originated mainly from the recent inputs and their total concentrations varied from 4.13 to $7215.24 \mathrm{ng} / \mathrm{g}$ with a mean of $336.13 \mathrm{ng} / \mathrm{g}$. Polychlorinated Biphenyls (PCBs) were associated with the usage of commercial products and the total concentrations of 125 congeners ranged from 2.21 to $4008.47 \mathrm{ng} / \mathrm{g}$ with a mean of $486.12 \mathrm{ng} / \mathrm{g}$. Residential Total Lifetime Carcinogenic Risk (TLCR) value, higher than the target excess individual lifetime risk $\left(1 \times 10^{-6}\right)$, was calculated to be of $22.6 \%$ for PAHs, 16.1\% for OCPs and 6. 5\% for PCBs respectively. Occupational TLCR, higher than the target excess individual lifetime risk was of $9.7 \%$ for PAHs, $6.5 \%$ for OCPs and 0\% for PCBs respectively. In all sampling sites, non-carcinogenic risks expressed as Total Hazard Quotient (THQ) for PAHs, OCPs and PCBs were always below 1. As a consequence, the carcinogenic and non-carcinogenic risks due to exposure to POPs in soil were very low even in such a typical petrochemical industrial area. In the study, the management and the risk assessment of POPs in a petrochemical industrial area close to a metropolis, were evaluated comprehensively.
\end{abstract}

(c) 2015 Elsevier B.V. All rights reserved.

\section{Introduction}

Persistent Organic Pollutants (POPs) form a diverse group of toxic substances, which cause serious concerns due to their semi-volatility, mobility in the environment, and potential to long-range transport and bioaccumulation. Soil plays an important role as a sink for these toxic chemicals (Hassanin et al., 2005; Meijer et al., 2002, 2003a). POPs can accumulate in the soil for a long period continuously affecting its quality, and ultimately threatening human health, especially of local population (Jones and De Voogt, 1999).

In the framework of the Stockholm Convention on POPs, a list of chemicals whose production, use and storage must be eliminated or severely restricted was established (UNEP, 2001). Nevertheless, the rapid industrialization and urbanization during the last decades, and the average daily consumption of over 84,000 tons of coal and

\footnotetext{
* Corresponding author.

** Correspondence to: G.-L. Yuan, State Key Laboratory of Biogeology and Environmental Geology, China University of Geosciences, Beijing 100083, China.

E-mail addresses: yerong@cugb.edu.cn (R. Ye), yuangl@cugb.edu.cn (G.-L. Yuan).
}

20,300 tons of petroleum fuels in Beijing (Peng et al., 2011), have resulted in significant environmental problems related to POPs contamination (Fu et al., 2008b; Li et al., 2005; Tang et al., 2005).

Data on the distribution of POPs in soil can help us to assess levels of pollution, identify sources of emission and evaluate the environmental health risks (Peng et al., 2011; Wu et al., 2011; Yang et al., 2012; Yuan et al., 2014). Previous studies have reported the presence of POP contaminants in the topsoils of urban/suburban Beijing, including Polycyclic Aromatic Hydrocarbons (PAHs) (Li et al., 2006; Liu et al., 2010; Peng et al., 2011, 2012; Tang et al., 2005; Wang et al., 2009b, 2010), Organochlorine Pesticides (OCPs) (Cheng et al., 2011; Li et al., 2005, 2008; Shi et al., 2009; Yang et al., 2010) and Polychlorinated Biphenyls (PCBs) (Fu et al., 2008b; Wu et al., 2011). However, few studies have been focused on the behavior of these three groups of POPs at the same time, especially within an industrial area close to a metropolitan area, such as the Yanshan petrochemical area in Beijing, China.

Yanshan petrochemical area was founded in the 1960s. It is located in southwest Beijing, $50 \mathrm{~km}$ away from the city center. Now there are dozens of factories refining crude oil and producing derivatives in this area, and about 30,000 inhabitants, including 16,000 petrochemical 
workers live there. Although Yanshan petrochemical area is far away from central Beijing, it has been gradually developed as a suburban area recently.

Chemical/petrochemical industries have been identified as important sources of emissions for wide-ranging chemical substances, including POPs (Kaisarevic et al., 2007; Nadal et al., 2011; Undeman et al., 2011; Wang et al., 2009a). In recent years, a lot of researchers have reported the concentrations, distributions and risk assessments of POPs in the topsoils of urban and industrial areas (Albanese et al., 2015; Dömötörová et al., 2012; Li et al., 2011; Nadal et al., 2011; Syed and Malik, 2011; Yuan et al., 2014). For an industrial heartland like Yanshan petrochemical area, POP contaminations of the topsoils may mainly resulted not only from emission of local industries but also from air inputs proceeding from the Beijing urban area (Wang et al., 2011b). It is essential to comprehensively understand the POP contamination levels, their sources and the human health risks associated to them.

In this study, we implemented a systematic study of legacy POPs in the topsoils of Yanshan petrochemical industrial area in Beijing, in order to: (1) systematically measure the concentration and investigate the distribution of POPs, including PAHs, OCPs and PCBs; (2) identify the possible sources of PAHs, OCPs and PCBs, respectively, by means of diagnostic ratios of congeners and multivariate statistical analysis; and (3) comprehensively evaluate the human health risks due to exposure to POPs in the topsoil.

\section{Methods}

\subsection{Sampling}

The total studied area was $30 \mathrm{~km}^{2}$. In September 2011, 31 topsoil samples $(0-20 \mathrm{~cm})$ were collected at Beijing petrochemical industrial area with $1 \times 1 \mathrm{~km}^{2}$ grids; the sampling sites belonged to both populated areas and environmental sensitive zones. At each sampling location, five sub-samples were collected with a stainless steel spade, and mixed thoroughly into a composite sample to reduce the random variation and produce a representative sample. The sampling location maps, produced by MapGis Software (version 6.7), is shown in Fig. 1. Soil samples were stored in a brown glass bottle (New Landmark Soil Equipment Co., China), and transported to the lab to be stored at $-20^{\circ} \mathrm{C}$ until extraction.

\subsection{Chemicals}

The USEPA priority 16 PAH standard solution $(1000 \mu \mathrm{g} / \mathrm{mL})$ was obtained from Sigma-Aldrich, St. Louis, MO (USA). The abbreviations of 16 PAHs are showed in Table S1, Supplementary Materials (abbreviation as $\mathrm{SM}$ ). In addition, 2-flurobiphenyl (2-FBP) was used as a surrogate standard (Supelco, Bellefonte, PA, USA). The 23 OCPs standard solution (listed in Table S1) was the product of Sigma-Aldrich, St. Louis, MO (USA). In addition, 2,4,5,6-Tetrachloro-Mxylene (TCMX) was used as a surrogate standard (Supelco, Bellefonte, PA, USA).
Five PCBs standard solutions were purchased from AccuStandard Inc. (New Haven, CT, USA). The PCB calibration mixtures were diluted, containing 125 congeners (in Table S1) with iso-octane to $20 \mathrm{ng} / \mathrm{ml}$ for each congener. The 125 PCB congeners represent the commercial mixtures of PCBs most widely used, such as Aroclor 1016, 1242, 1248 1254, 1260 reported on WHO-ECEH and IPCS consultation (Ahlborg et al., 1994). TCMX was also used as a surrogate standard. Standard reference material GBW08307 (reference soil for PCBs congeners analysis, including CB-28, 52, 77, 81, 101, 118, 114, 105, 138, 153, 167, 156, 157 and 180) was obtained from the National Research Center for Certified Reference Materials of China.

Silica gel (100-200 mesh) (Qingdao Haiyang Chemical Co., Qindao, China) was activated in a drying oven at $550{ }^{\circ} \mathrm{C}$ for $6 \mathrm{~h}$. Anhydrous sodium sulfate (Beijing Chemical Factory, China) was heated at $600{ }^{\circ} \mathrm{C}$ for $12 \mathrm{~h}$ and then was used to eliminate organic contamination. Methanol, dichloromethane and acetone were the products of Beijing Chemical Factory, China (analytical grade). The other solvents were of pesticide grade and were purchased from J. T. Baker (Phillipsburg, NJ, USA).

\subsection{Extraction and cleanup}

Ten grams of each soil sample containing one of the surrogate standards was mixed with sufficient anhydrous sodium sulfate, and then together placed into a free-flowing powder. Each sample was extracted with $30 \mathrm{~mL}$ of hexane/dichloromethane $(1: 1, \mathrm{vol} / \mathrm{vol})$ by ultrasonication for $4 \mathrm{~min}$ and then centrifuged the samples at $3000 \mathrm{~g}$, this process was repeated three times and extracts were combined. The concentrated extracts were evaporated to $1 \mathrm{~mL}$ in a KudernaDanish concentrator under a gentle $\mathrm{N}_{2}$ stream for cleanup. Each sample was separately extracted three times for cleanup and analysis of PAHs, OCPs and PCBs. Before extraction, 2-FBP and TCMX were added to the accurately weighed soil samples as surrogate standards for PAHs, OCPs and PCBs individually, and balanced at desiccator for 2 hours. Cleanup of PAHs, OCPs and PCBs individually followed the modified methods of our previous reports (Fu et al., 2008a, 2008b, 2009a), and the detailed processes are described in SM.

\subsection{Analysis and quality control}

PAHs, OCPs and PCBs were individually measured with an Agilent 6890 series Gas Chromatograph (GC) coupled with an Agilent 5973 mass spectrometer, using electron impact ionization source in SIM mode. The detailed analytic conditions for PAHs, OCPs and PCBs followed those described in our previous reports (Fu et al., 2008a, 2008b, 2009a; Yuan et al., 2014) with a $30 \mathrm{~m}$ DB-5MS (30 $\mathrm{m} \times 0.25 \mathrm{~mm}$ i.d., $0.25 \mu \mathrm{m}$ film thickness) capillary column. As shown in Table S1 (in SM), 16 PAHs, 23 OCPs and 125 PCBs were detected.

To demonstrate lack of interference and cross-contamination, a procedural blank in parallel with every set of six samples was also run to further check for interference and cross-contamination. Duplicate
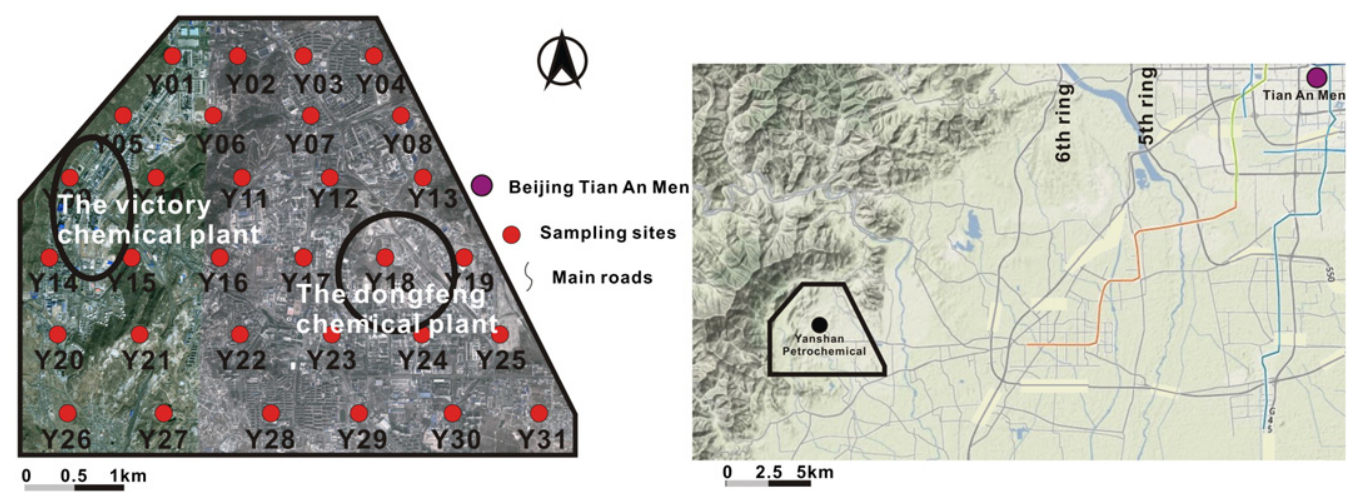

Fig. 1. Soil sampling sites in the Beijing southeast chemical industrial area. 
samples in the laboratory were analyzed along with regular samples to determine repeatability and reproducibility, for additional qualitycontrol assessment to ensure valid results. Instrument stability and relative response factor variance were determined by analyzing the calibration standard solutions in each sample batch.

Quantification of PAHs, OCPs and PCBs were individually performed using an external standard method. The quality control for analysis of PAHs and OCPs followed the previous reports (Yuan et al., 2014). The detail methods and quality controls for PCBs analysis are shown in SM. The Limits of detection (LOD) were determined as a signal-to-noise ratio of 3:1, and ranged from 0.03 to $3.15 \mathrm{ng} / \mathrm{ml}$ for PAHs, 0.03 to 0.93 $\mathrm{ng} / \mathrm{ml}$ for OCPs, and 0.01 to $1.72 \mathrm{ng} / \mathrm{ml}$ for PCBs respectively.

The matrix spike recoveries of the 16 PAHs were within the range of $76-105 \%$ with a standard deviation of $10 \%$, and the recovery of the 2 FBP surrogate in all samples was in the range of $70-92 \%$ for all of the samples. The matrix spike recoveries of the 23 OCPs were between 70 and $102 \%$ with a standard deviation of $7.0 \%$, and the recoveries of TCMX surrogate were in the range of 70-92\%. The matrix spike recoveries of the 125 PCB congeners (including some coeluting PCB congeners) were within $70 \%-106 \%$, with $12 \%$ standard deviation, and the recovery of TCMX surrogate in all samples was within the range of $70-95 \%$. The recoveries of the surrogate were satisfactory and no correction of analytical data was applied to the samples.

\subsection{Data analysis and mapping}

All concentrations in the study were expressed on a dry weight basis. In cases where the compounds were present below the detection limit, missing concentration values were considered as equal to one third of the detection limit in order to minimize an overestimation of samples $(\mathrm{ND}=1 / 3 \mathrm{LOD})$. Statistical analyses were performed in SPSS 19.0 for Windows (SPSS, USA). Level of significance was set at a probability lower than 0.05. Kolmogorov-Smirnov (K-S) test was checked for normal distribution, concentrations of PAHs and OCPs were logtransformed to achieve normal distribution for some concentration parameters did not follow a normal distribution, and composition ratio of PCBs at each sample was normalized to the percentage of homologues. Multivariate statistical techniques, such as Factor Analysis (FA) and Cluster Analysis (CA), are powerful tools for distinguishing among the possible sources of observed POPs (Fu et al., 2008b; Jiao et al., 2012; Wang et al., 2009b; Wu et al., 2011; Yuan et al., 2014). The Principal Component Analysis (PCA) with varimax rotation was used for FA to extract components with Eigenvalues greater than 1. Rcluster analysis was performed by Spearman correlations, and the Within-groups linkage distance 15 was used to define the greater association between the variables.

In addition to the statistical analyses, diagnostic ratios were used to distinguish the sources of emission and pollution inputs history (Ma and Zhou, 2011; Wang et al., 2011a; Yuan et al., 2014). MapGis 6.7 software was used to map the distribution of POPs by using Universal Kriging Interpolation with square directions, and ten intervals were tentatively defined to divide the concentration.

\subsection{Risk assessment}

Carcinogenic risks associated with POPs exposure were based on the deterministic approach from USEPA's Risk Assessment Guidance for Superfund (RAGS) methodology (Cachada et al., 2012; Rovira et al., 2010; USEPA, 1991). The potential exposure to POPs in topsoils of residential and industrial areas was separately calculated by exposure route (ingestion, dermal absorption and inhalation of particulates) as described in the USEPA screening level equations for preliminary remediation goals (USEPA, 2013). Two types of land uses were considered for carcinogenic risk and non-cancer risk (residential and occupational). The concentrations of all individual POPs for the calculation were translated into $\mathrm{mg} / \mathrm{kg}$. The human total lifetime cancer risk of POPs was individually calculated for 7 PAHs, 18 OCPs and 4 dioxin-like PCBs (PCB $81,105,118,157)$, which Chronic Oral Slope Factors $\left(\mathrm{CSF}_{\mathrm{o}}\right)$ and Chronic Inhalation Unit Risk (IUR) were already established by USEPA (2013). Then, the cancer risks of PAHs, OCPs and PCBs were obtained respectively.

The carcinogenic risks for ingestion and dermal adsorption were calculated by multiplying the predicted oral or dermal exposure by the $\mathrm{CSF}_{\mathrm{o}}$, since no $\mathrm{CSF}_{\mathrm{d}}$ of dermal adsorption has been established for these compounds. Cancer risks for inhalation of soil particulates were calculated by multiplying the exposure by the predicted chronic IUR.

Total Lifetime Carcinogenic Risks (TLCR) were obtained by summing the individual risks calculated for the three exposure routes as Eq. (1), including risks for ingestion, dermal adsorption and inhalation (USEPA, 2013). Both industrial occupational exposure risks and residential exposure risks were calculated for each sampling site, since all of the sites are industrial areas, and are also nearby residential areas, where the recreational activities are likely to happen. The residential exposure risks were calculated as Eqs. (2), (3) and (4). The occupational exposure risks adopted the land use of the composite worker soil, and were calculated as Eqs. (5), (6) and (7).

Furthermore, Total Equivalent Quantity (TEQ) was used to quantify the toxicity level and carcinogenic potential of PAHs and PCBs (Van den Berg et al., 2006). Each PAH and PCB compound has a different carcinogenic potential. In the case, the individual toxic concentrations of 16 PAHs and 4 dioxin-like PCBs (CB-81,105,118,157) and TEQ concentrations of PAHS and PCBs were calculated, respectively. And TEQ was defined by the sum of the concentrations of individual pollutants multiplied by their Toxic Equivalency Factors (TEF) (Van den Berg et al., 2006) as Eq. (8). The descriptive statistics of calculated TEQ for PAHs and PCBs are listed in Tables S22 and S23 (in SM).

Cancer risks:

$\mathrm{TLCR}=\mathrm{TR}_{\text {Ingestion }}+\mathrm{TR}_{\text {Inhalation }}+\mathrm{TR}_{\text {Dermal contact }}$.

Residential:

$$
\begin{aligned}
& \mathrm{TR}_{\text {Ingestion }}=\frac{\mathrm{CSF}_{\mathrm{o}} \times \mathrm{Cs} \times 10^{-6} \mathrm{~kg} / \mathrm{mg} \times \mathrm{EF} \times \mathrm{IFS}_{\mathrm{adj}}}{\mathrm{AT} \times \mathrm{LT}} \\
& \mathrm{TR}_{\text {Dermal contact }}=\frac{\mathrm{CSF}_{\mathrm{o}} \times \mathrm{Cs} \times 10^{-6} \mathrm{~kg} / \mathrm{mg} \times \mathrm{EF} \times \mathrm{DFS}_{\mathrm{adj}} \times \mathrm{ABS}_{\mathrm{d}}}{\mathrm{GIABS} \times \mathrm{AT} \times \mathrm{LT}} \\
& \mathrm{TR}_{\text {Inhalation }}=\frac{\mathrm{CS} \times \mathrm{ED}_{\mathrm{r}} \times \mathrm{EF} \times \mathrm{ET} \times 1 / \mathrm{PEF} \times \mathrm{IUR}}{\mathrm{AT} \times \mathrm{LT}} .
\end{aligned}
$$

Occupational:

$\mathrm{TR}_{\text {Ingestion }}=\frac{\mathrm{CSF}_{\mathrm{o}} \times \mathrm{Cs} \times \mathrm{IRS} \times 10^{-6} \mathrm{~kg} / \mathrm{mg} \times \mathrm{EF} \times \mathrm{ED}}{\mathrm{AT} \times \mathrm{LT} \times \mathrm{BW}}$

$\mathrm{TR}_{\text {Dermal contact }}$

$$
=\frac{\mathrm{CSF}_{\mathrm{o}} \times \mathrm{Cs} \times 10^{-6} \mathrm{~kg} / \mathrm{mg} \times \mathrm{EF} \times \mathrm{ED} \times \mathrm{SA} \times \mathrm{AF} \times \mathrm{ABS}_{\mathrm{d}}}{\mathrm{GIABS} \times \mathrm{AT} \times \mathrm{LT} \times \mathrm{BW}}
$$

$\mathrm{TR}_{\text {Inhalation }}=\frac{\mathrm{CS} \times \mathrm{ED} \times \mathrm{EF} \times \mathrm{ET} \times(1 / \mathrm{PEF}) \times \mathrm{IUR}}{\mathrm{AT} \times \mathrm{LT}}$

$\mathrm{TEQ}=\sum\left[\mathrm{C}_{\mathrm{i}}\right] \times \mathrm{TEF}_{\mathrm{i}}$

where

$\mathrm{TR}_{\text {Ingestion }}$ Total cancer risk through ingestion

$\mathrm{TR}_{\text {Dermal contact }}$ Total cancer risk through dermal contact

$\mathrm{TR}_{\text {Inhalation }}$ Total cancer risk through inhalation

$\mathrm{CSF}_{\mathrm{o}} \quad$ Chronic oral Slope Factor $(\mathrm{mg} / \mathrm{kg}-\mathrm{d})^{-1}$

Cs Constituent concentration at soil $(\mathrm{mg} / \mathrm{kg})$

$\mathrm{AT}_{\mathrm{r}} \quad$ Averaging time $(\mathrm{d} / \mathrm{yr})$

LT Lifetime (yr) 
$\mathrm{EF}_{\mathrm{r}} \quad$ Exposure frequency $(\mathrm{d} / \mathrm{yr})$

$\mathrm{IFS}_{\text {adj }}$ Resident soil ingestion rate-age-adjusted (mg-yr $/ \mathrm{kg}-\mathrm{d}$ )

BW Average body weight $(\mathrm{kg})$

ED Resident exposure duration (yr)

$\mathrm{ED}_{\mathrm{r}} \quad$ Exposure duration $(\mathrm{yr})$

$\mathrm{ET}_{\mathrm{rs}} \quad$ Soil exposure time $(\mathrm{h} / \mathrm{h})$

PEF Particulate emission factor $\left(\mathrm{m}^{3} / \mathrm{kg}\right)$

IUR Chronic inhalation unit risk $\left(\mathrm{mg} / \mathrm{m}^{3}\right)^{-1}$

$\mathrm{DFS}_{\text {adj }} \quad$ Resident soil dermal contact factor-age-adjusted (mg-yr/kg-d)

$\mathrm{ABS}_{\mathrm{d}} \quad$ Fraction of contaminant absorbed dermally from soil (unitless)

SA Skin surface area available for contact $\left(\mathrm{cm}^{2} / \mathrm{d}\right)$

AF Adherence factor of soil to skin $\left(\mathrm{mg} / \mathrm{cm}^{2}\right)$

GIABS Fraction of contaminant absorbed in gastrointestinal tract (unitless)

$\mathrm{C}_{\mathrm{i}} \quad$ Concentration of individual pollutants.

Once carcinogenic exposure was assessed, the non-cancer risks were calculated as Hazard Quotient (HQ) in relation to Dermal Reference Dose, Oral Reference Dose $\left(\mathrm{RfD}_{\mathrm{o}}\right)$ and Inhalation Reference Dose $\left(\mathrm{RfC}_{\mathrm{i}}\right)$ (USEPA, 2013). Since no Dermal Reference Dose has been established for the pollutant study, this value was assumed to be equal to the $\mathrm{RfD}_{\mathrm{o}}$ (USEPA, 2013). The HQ for incidental ingestion, dermal absorption of soil and inhalation of soil particulates was ascertained being correlated with $\mathrm{RfD}_{\mathrm{o}}$ and $\mathrm{RfC}$. The values of $\mathrm{RfD}_{\mathrm{o}}$ and $\mathrm{RfC}_{\mathrm{i}}$ were established by USEPA (2013). Total Hazard Quotient (THQ) was obtained by summing the individual risks of the three exposure routes. According to the equations listed in SM, the HQ for residential children and adults were individually calculated for individually 6 PAHs, 15 OCPs and 4 dioxin-like PCBs. The HQ for inhalation of PAHs and OCPs was calculated for Nap and $\sum$ Chlordane because $\mathrm{RfC}_{\mathrm{i}}$ was available only for them among all compounds. Risks for non-carcinogenic effects of contaminants from occupational exposure were also calculated as $\mathrm{HQ}$ and the equations were described in SM together with the parameters used for calculation.

\section{Results and discussion}

\subsection{PAHs}

The measured concentrations and summary statistics of 16 PAHs in topsoils are listed in Table S2 (in SM). The PAH concentrations ranged from 35.29 to $6120.22 \mathrm{ng} / \mathrm{g}$, with a mean of $906.11 \mathrm{ng} / \mathrm{g}$, which was lower than in other urban areas of Beijing (Li et al., 2006; Liu et al., 2010; Peng et al., 2011), and higher than other reported chemical/petrochemical area (Nadal et al., 2007). The mean concentrations of phenanthrene (Phe), naphthalene (NaP), fluorene (Fl) were above $100 \mathrm{ng} / \mathrm{g}$. In particular, the maximum concentration of $\mathrm{Fl}$ reached $3068.23 \mathrm{ng} / \mathrm{g}$, with a mean of $103.66 \mathrm{ng} / \mathrm{g}$. The concentration of 7 carcinogenic PAHs accounted for $26.3 \%$ of the total PAHs. As the most potential carcinogenic $\mathrm{PAH}$, benzo[a]pyrene (BaP) varied from $<0.01$ to $647.56 \mathrm{ng} / \mathrm{g}$ with a mean of $44.97 \mathrm{ng} / \mathrm{g}$. In addition, concentrations of PAHs with 2-3 rings were relatively higher than the 4-6 rings. Due to lack of National Standards for China, the Canadian Soil Quality Guidelines (CSQGs) (CCME, Canadian Council of Ministers of the Environment, 2007) and Netherlands "Maximum Permissible Concentrations (MPCs)" (Kalf et al., 1997) were used to evaluate the levels of PAHs concentrations in the case, since the threshold values of CSQGs and MPCs were established based on a long history of experimental eco-toxicological data. As a result, the concentrations of Nap and $\mathrm{BaP}$ in all sites were lower than the threshold values of CSQGs; Flu, BaA, BkF and BghiP were all lower than that of MPCs, but Nap, Phe, Ant and BaP exceeded the corresponding value of MPCs.

Spatial distribution of the $\sum$ PAHs is shown in Fig. S1 (in SM). In most of study the areas, the $\sum$ PAHs concentration was lower than $1500 \mathrm{ng} / \mathrm{g}$. The peak values appeared in sites Y09 close to the Victory chemical plant and site Y18 close to the Dongfeng chemical plant. The two plants produce rubber and chemical fiber carpet respectively, which may be the source of PAHs. Thus, industrial activities of petrochemical plants can be recommended as the mainly sources of PAHs in study area.

The PCA with varimax rotation was used to analyze the relationship of PAHs in all samples on the basis of concentration. Two principal components with eigenvalues greater than 1 represented $78.8 \%$ of the total variance. As shown in Fig. 2, the PAHs were clearly separated into two groups (I and II) on the factor loading plot. Low molecular weight PAHs such as acenaphthylene (Acy), acenaphthene (Ace), Nap and $\mathrm{Fl}$, were included into Group II and were strongly correlated with PC2, while the rest of 12 high molecular weight PAHs (Group I) were correlated with PC1 explaining the $58.4 \%$ of the total variance. The plot of the CA showed a similar grouping (Fig. S2, in SM). Generally, Acy, Ace, Nap and Fl are mainly originated from petroleum spills (Dobbins et al., 2006; Marr et al., 1999), thus PC2 can represent the petrolic source. At the same time, benzo[b]fluoranthene (BbF), benzo[g,h,i]perylene (BghiP) and indeno [1,2,3-cd]pyrene (INP) are typical markers of the gasoline and diesel engines discharge and they can be considered the emblematic tracers of automotive traffic (Duval and Friedlander, 1981; Guo et al., 2003; Harrison et al., 1996; Li and Kamens, 1993), and Phe, fluoranthene (Flu), pyrene (Pyr), and anthracene (Ant) are predominantly emitted by coal and biomass combustion (Harrison et al., 1996; Mastral et al., 1996; Zhang et al., 2008). It was reasonable to suggest that the PC1 represented the mixed contribution of different emission sources.

According to the ratio of Ant/(Ant + Phe), the sources of PAHs could be qualitatively distinguished from combustion or crude oil pollution. However, it was unable to identify some specific sources, because the photolysis of Ant is faster than that of Phe (Yunker et al., 2002). In the case, the relationships among Flu, Pyr, Ant and Phe, as well as InP, BghiP, benz[a]anthracene (BaA) and chrysene (Chr), were recently used to determine the sources (Jiang et al., 2009; Ma and Zhou, 2011; Wang et al., 2011a). On the basis of these methods, the ratios of PAHs were calculated and plotted as shown in Fig. S3 (in SM). The plot of $\mathrm{Flu} /(\mathrm{Flu}+\mathrm{Pyr}) \mathrm{vs}$. Ant/(Ant + Phe $)$ suggested that the sources of the PAHs were mainly originated from petroleum combustion which was also indicated by the plot of $\operatorname{InP} /(\operatorname{InP}+$ BghiP) vs. BaA/(BaA + Chr $)$.

\subsection{OCPS}

Concentrations of the 23 OCPs obtained in 31 surface soils are summarized in Table S3 (in SM). The total OCP concentrations varied from 4.13 to $7215.24 \mathrm{ng} / \mathrm{g}$, with a mean of $336.13 \mathrm{ng} / \mathrm{g}$. In China, dichlorodiphenyltrichloroethanes (DDTs) and hexachlorocyclohexanes (HCHs) were the two most widely used OCPs in the past (Lin et al.,

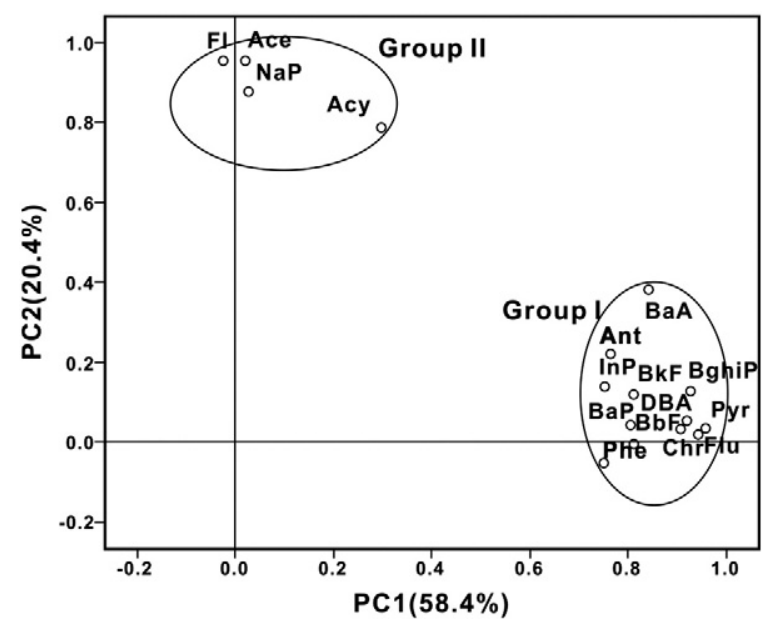

Fig. 2. Two-dimensional plot of the principal component loadings for PAHs. 
2012). In the study, the concentrations of DDx (DDTs, sum of o, $\mathrm{p}^{\prime}-\mathrm{DDE}$, p, $\mathrm{p}^{\prime}$-DDE, o, $\mathrm{p}^{\prime}$-DDD, $\mathrm{p}, \mathrm{p}^{\prime}$-DDD, o, $\mathrm{p}^{\prime}$-DDT, $\mathrm{p}, \mathrm{p}^{\prime}$-DDT) accounted for 81.7\% of the total OCPs in topsoils, and they were significantly higher than those of HCHs (4.8\%). Moreover, p, $\mathrm{p}^{\prime}$-DDT and p, $\mathrm{p}^{\prime}$-DDD were the main contaminants of DDx, with a mean of 115.73 and $97.64 \mathrm{ng} / \mathrm{g}$, respectively, followed by o, $\mathrm{p}^{\prime}$-DDT. The concentrations of DDx and $\mathrm{HCHs}$ in the study area were higher than those in urban soils of Beijing (Li et al., 2008; Yang et al., 2010), but they were much lower than those in some special area, such as pesticide production plant (Yang et al., 2009) and agricultural soils in Beijing (Shi et al., 2005). According to the Environmental Quality Standard for Soils (EQSSs) of China (Ministry of Environmental protection, 1995), the HCHs concentrations can meet the secondary standard overall, and the DDx concentrations exceeded the three-level standard in EQSSs.

The spatial distribution of $\Sigma$ OCPs is shown in Fig. S4 (in SM). The highest concentration was observed near the Victory chemical plant (Y09), with a gradually decreasing trend away from the plant. Such a decreasing trend can be explained by the high organic carbon content fixing the deposition of OCPs in soil and preventing their volatility (Cornejo et al., 2005; Meijer et al., 2003b).

The PCA was performed to analyze the relationship among OCPs based on the concentration. The factor loading plot is shown in Fig. 3, and two principal components together represented $65.5 \%$ of the total variance. Among the 23 OCPs, o, $\mathrm{p}^{\prime}$-DDE, p, p'-DDE, p, $\mathrm{p}^{\prime}$-DDD, o, $\mathrm{p}^{\prime}$-DDT, $\mathrm{p}, \mathrm{p}^{\prime}$-DDT, o, $\mathrm{p}^{\prime}$-DDD, $\alpha$-HCH, $\beta-\mathrm{HCH}, \gamma-\mathrm{HCH}, \delta$-HCH and Aldrin belong to Group I, and they were strongly correlated with PC1. While, on the other hand, HCB, Endrin, trans-Nonachlor, cis-Nonachlor (Group II) were correlated with PC2. Concentration of the 11 OCPs in Group I accounted for $88.2 \%$ of total OCPs and concentration of the 4 OCPs in Group II accounted for $9.7 \%$ of the total OCPs. Finally, the concentration of the remaining 8 OCPs held $2.1 \%$ of the total OCPs. Apparently, the pollutants in Group I dominated the OCPs composition in the study area. A CA was performed (Fig. S5, in SM) and its results were similar to that of the PC.

The results of PCA and CA showed that HCHs and DDx dominated Group I, occupying a high proportion of $\Sigma$ OCPs (86.5\%). Therefore, source identification for OCPs could be focused on DDx and HCHs. Commonly, the o, $\mathrm{p}^{\prime}$-DDT/p,p'-DDT ratio is used to distinguish whether the source of the DDx is technical or agricultural dicofol (Li et al., 2008; Qiu et al., 2005; Yang et al., 2009), and the p,p'-(DDE + DDD)/ $\mathrm{p}, \mathrm{p}^{\prime}$-DDT ratio is used to determine the DDx sources and its input history (Li et al., 2008; Qiu et al., 2005; Yang et al., 2009). In this case, the concentration ratios of o,p'-DDT/p,p'-DDT varied from 0 to 745.75 (mean of 1.27), and the ratios were lower than 0.3 in $16.1 \%$ of the samples, suggesting that the DDx was mainly from the use of agricultural dicofol. The concentration ratios of $\mathrm{p}, \mathrm{p}^{\prime}-(\mathrm{DDE}+\mathrm{DDD}) / \mathrm{p}, \mathrm{p}^{\prime}-\mathrm{DDT}$

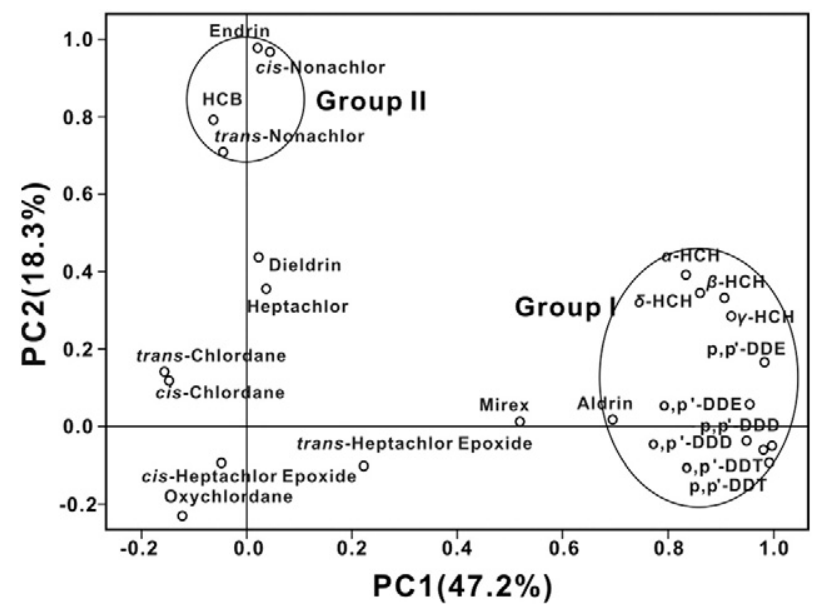

Fig. 3. Two-dimensional plot of the principal component loadings for OCPs. ranged from 0 to 518.85 (mean of 0.95 ), and the ratios were higher than 1 in $35.5 \%$ of the sample, suggesting that the DDx mainly originated from a recent input. Since in the northwest of the study area, there was a chemical plant, now dismantled, producing pesticides and associated materials, the detected DDx in this case may have resulted from the leakage of hazardous materials from the plant.

At the same time, $\alpha / \gamma-\mathrm{HCH}$ was used to identify the pollution sources of HCHs (Li et al., 2008; Zhang et al., 2004), and $\beta /(\alpha+\gamma)$-HCH for determining the input history (Zheng et al., 2009). In 38.7\% of the samples, the ratios of $\alpha / \gamma-\mathrm{HCH}$ higher than 4.6 suggested that the major pollution source was lindane used in agriculture. In $41.9 \%$ of the samples, the ratios of $\beta /(\alpha+\gamma)$-HCH higher than 1 suggested that $\mathrm{HCH}$ in half of the sampling sites was influenced by the recent input of lindane. Although technical HCH was banned in China in $1983,1.14 \times 10^{4}$ tons of lindane was produced between 1983 and 2000, and it was allowed to be used in restricted ways (Li et al., 2001), such as the prevention of locust in Beijing, Tianjin and Heilongjiang.

\subsection{PCBs}

Wu et al. (2011) reported that the concentration of PCBs in urban soils of Beijing was more than twice the soil background of the world, and significantly higher than the average level in China (Ren et al., 2007). Nevertheless, few studies have focused on PCBs in the topsoils from Beijing petrochemical industrial areas.

In this study, the concentrations of $\sum$ PCBs ranged from 2.21 to $4008.47 \mathrm{ng} / \mathrm{g}$, with a mean value of $486.12 \mathrm{ng} / \mathrm{g}$. This value was 2 and 3 orders of magnitude higher than those of Beijing urban soil and global background soil, respectively (Wu et al., 2011). Among the 31 topsoil samples, 5 samples exceeded the intervention values for $\sum$ PCBs concentration according to the Soil Remediation Circular (VROM, 2009).

Among the 125 congeners detected, CB-194 was the most abundant congener, with the maximum and mean concentration of 505.03 and $47.40 \mathrm{ng} / \mathrm{g}$, respectively, followed by CB-28/31, 82/110, 7/9, 209 and 199/201. As shown in Table S4 (in SM), the descriptive statistics of the homologues of the PCB congeners in 31 topsoil samples were analyzed. Octa-CBs showed the highest concentration with a mean value of $96.94 \mathrm{ng} / \mathrm{g}$, followed by penta-CBs $(81.49 \mathrm{ng} / \mathrm{g})$, tetra-CBs $(75.67 \mathrm{ng} / \mathrm{g})$ and tri-CBs $(75.50 \mathrm{ng} / \mathrm{g}$ ). Fig. 4 showed the proportion of different homologues at each sampling site. Overall, the low-chlorinated PCBs were dominant in topsoils. The major homologues were di- to pentaCBs. Among of them, tri-CBs accounted for $0.01-95.4 \%$, with a mean value of $33.3 \%$, followed by di-CBs and tetra-CBs. The levels of highpolychlorinated homologues, such as nona-CBs to dec-CBs, were relatively low. Compositions of $\mathrm{PCB}$ homologues were similar to the

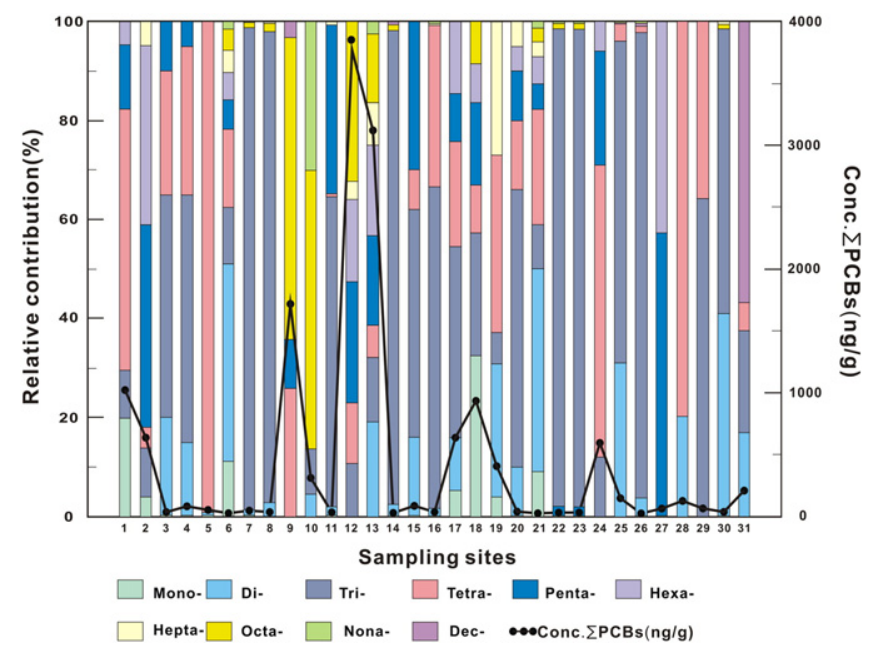

Fig. 4. $P C B$ homologues as a proportion of total PCBs at each site. 
results of previous studies in Beijing (Wu et al., 2011). However, the concentrations of $\sum$ PCBs in the study area were higher than those in some urban areas in China (Fu et al., 2009b; Jiang et al., 2011b; Li et al., 2012; Wang et al., 2008), and also in different industrial areas worldwide. For instance, Motelay-Massei et al. (2004) reported a concentration of $150 \mathrm{ng} / \mathrm{g}$ in soils collected in industrial areas in Notre-Dame de Gravenchon (France). Capuano et al. (2005) found PCBs concentrations $(0.7-30.1 \mathrm{ng} / \mathrm{g})$ near a solid waste incinerator in Reggio Emilia (Italy). Furthermore, in Eastern Romania, the soils collected in the vicinity of a waste-disposal site contained PCB concentration of $278 \mathrm{ng} / \mathrm{g}$ (Dragan et al., 2006). Low concentrations were also found in industrial area of Serbia and Spain, respectively (Kaisarevic et al., 2007; Nadal et al., 2011).

The spatial distribution of PCB concentration in topsoils of the study area is shown in Fig. S6 (in SM). There were two noticeable sites with concentrations of $\sum$ PCBs higher than $1000 \mathrm{ng} / \mathrm{g}$ near both the Victory (Y09) and the Dongfeng (Y18) chemical plants. The concentration of PCBs at site Y18 even reached to $4008.47 \mathrm{ng} / \mathrm{g}$. However, the concentrations of PCBs at the other sites were at a relatively low level from 2.21 to 976.71. Therefore, it is most likely that petrochemical plants were responsible for the PCBs pollution since these compounds were widely used as insulating or lubricating oils in plastic, resin and rubber industry. In previous studies, high concentrations of PCBs had already been observed in the soil around petrochemical industrial plants (Kaisarevic et al., 2011; Nadal et al., 2007).

The composition ratio of PCBs in each sample was normalized to the percentage of homologues according to that given by the commercial Aroclor products (Cachada et al., 2009; Wu et al., 2011), and a PCA was performed to find out the source relationship with Aroclor 1260, 1254, 1248, 1242 and 1016. The factor loading plot is shown in Fig. 5, and two extracted principal components (PC1 and PC2) explained $67.8 \%$ of the total variance. PC1 accounted for $48.5 \%$ of the total variance and was highly correlated with Aroclor 1016 and 1242, which was dominated by di-, tri- and tetra-CBs and PC2 influenced $19.3 \%$ of the total variance and was related to the Aroclor 1248, which was predominated by tri-, tetra- and penta-CBs. Among the 31 topsoils, 20 samples were classified into a group associated with Aroclor 1016 and 1242, 6 associated with Aroclor 1248 and only 2 associated with Aroclor 1254 and 1260. The grouping of CA (Fig. S7, in SM) was consistent with that of PCA. The compositions of PCBs in the study were mainly consistent with those of Aroclor 1016, 1242 and 1248 in previous reports (Wu et al., 2011). Additionally, the compositional patterns of PCB homologues (Fig. 4) also indicated that tri-CBs, tetra-CBs and penta-CBs were the dominant contaminants in the Yanshan petrochemical topsoils and these PCB homologues were highly associated with Aroclor 1016, 1242 and 1248 .

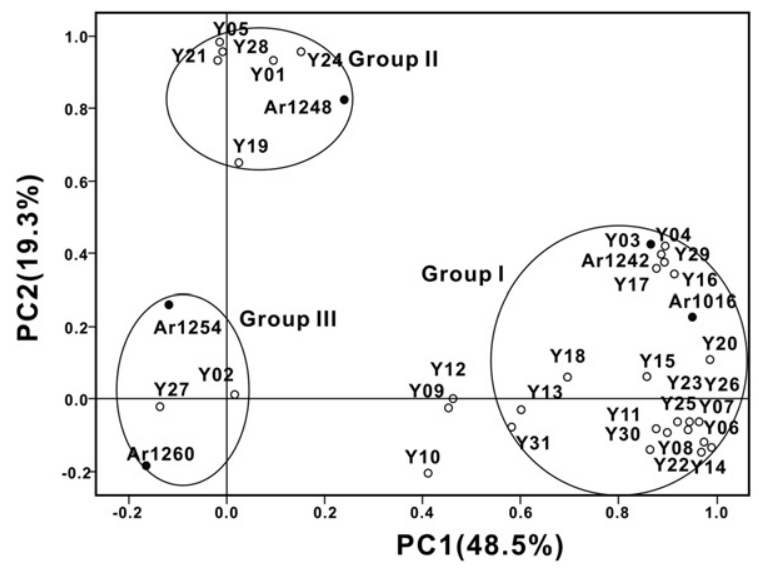

Fig. 5. Two-dimensional plot of the principal component loadings for PCBs.

\subsection{Health risk assessment}

\subsubsection{Carcinogenic risks}

For residential PAH exposure, the risks for the 7 USEPA carcinogenic PAHs were calculated individually for the 31 sampling sites. The exposure calculation parameters for the equations are shown in Tables S5 and S6 (in SM). The results of the calculations are summarized in Tables S9 and S10 (in SM) and Fig. 6. The highest risks for PAHs were from the ingestion exposure, followed by dermal contact, and the inhalation. The threshold value of $1 \times 10^{-5}$ (Albanese et al., 2015; Health Canada, 2010) and the target excess individual lifetime risk $\left(1 \times 10^{-6}\right)$ (Peng et al., 2011; USEPA, 2013) were adopted in this cancer risk assessment. Among the 31 sampling sites in this study, the maximum TLCR of $\sum$ PAHs was $1.29 \times 10^{-5}$ with the mean at $1.11 \times 10^{-6}$, which was lower than the value of soil from a developing recreational area where was an industrial area in Beijing (Yuan et al., 2014). Only 1 sampling site (3.2\%) possessed TLCR value higher than $1 \times 10^{-5}$ which indicated a "not negligible" risk level (Health Canada, 2010), and 6 sampling sites (19.4\%) possessed TLCR values higher than $1 \times 10^{-6}$ which indicated an acceptable risk level (USEPA, 2013). These sites were mainly around both the Victory (Y5, Y9 and Y10) and the Dongfeng chemical plants (Y17 and Y18). Although the result of risk assessment showed that the PAH pollution was at a low degree, some specific concerns were necessary due to PAHs carrying higher cancer risk than exposure to OCPs and PCBs as discussed below.

For OCPs, the cancer risk parameters are shown in Tables S5 and S7 (in SM). The TLCR values are calculated based on the $\mathrm{CSF}_{\mathrm{o}}$ and IUR

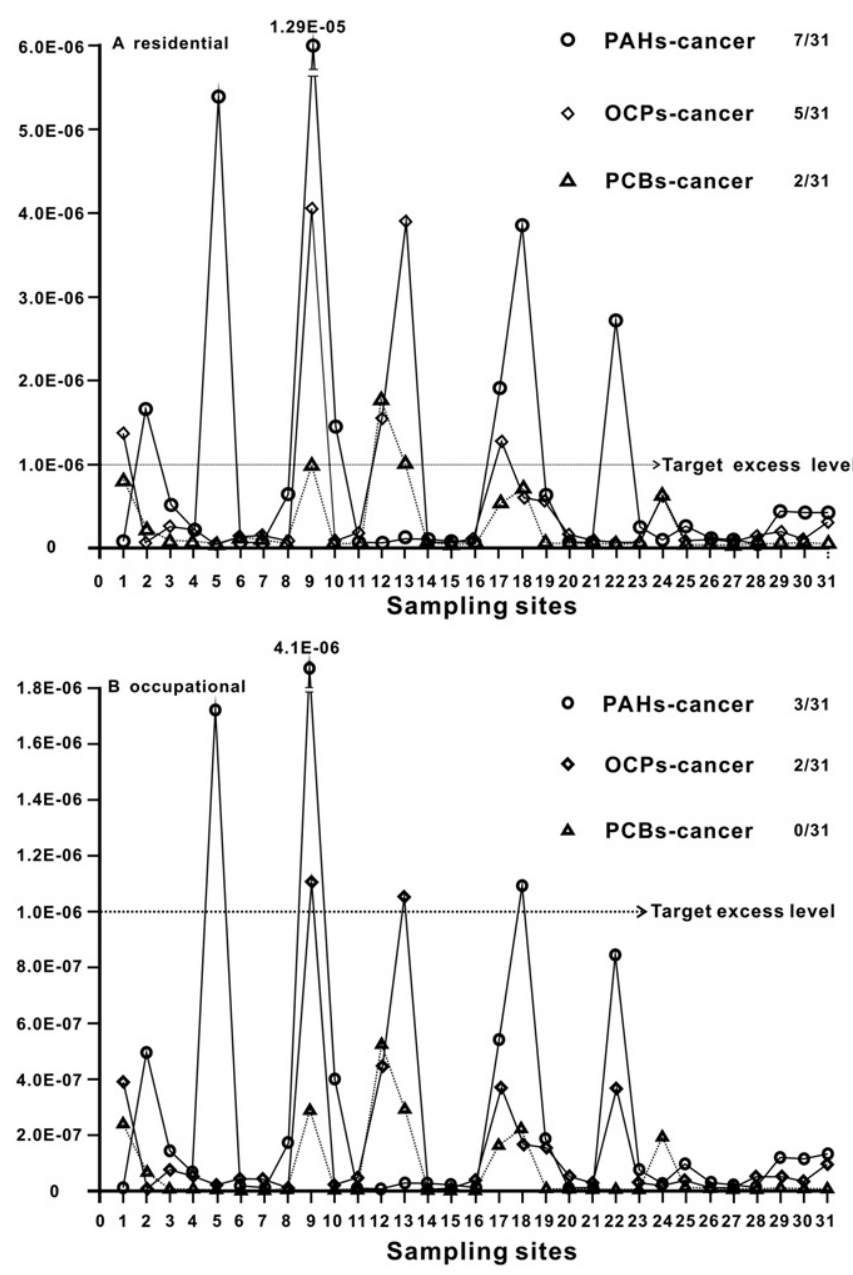

Fig. 6. Spatial distribution of carcinogenic risk due to PAHs in the topsoil of Beijing's chemical industrial area. 
values (USEPA, 2013). As shown in Tables S9 and S10 and Fig. 6, the TLCR values for OCPs in this case were always below $1 \times 10^{-5}$, and the highest value was $4.06 \times 10^{-6}$ with mean value at $5.29 \times 10^{-7}$, which was higher than the value reported by Yuan et al. (2014). 5 sites (16.1\%) possessed risk values higher than $1 \times 10^{-6}$, and 3 of these 5 sites were observed near the Dongfeng chemical plant (Y12, Y13 and Y17).

For the 4 dioxin-like PCBs, the calculation method of residential exposure risk was used in the same way as that for PAHs and OCPs. The parameters are shown in Tables S5 and S8 (in SM) and the cancer risk values are shown in Tables S9 and S10 and Fig. 6. The maximum and mean TLCR values for PCB were all lower than $1 \times 10^{-5}$, as $1.80 \times 10^{-6}$ and $2.20 \times 10^{-7}$, respectively. Only 2 sites (6.5\%) showed risk values higher than $1 \times 10^{-6}$, and the 2 sites were observed near the Dongfeng chemical plant (Y12 and Y13). This result suggested that the PCB pollution was at a safe level. As the high TLCR values for both OCPs and PCBs around the Dongfeng chemical plant, some attention should be given to this area.

For occupational exposure, the cancer risks of POPs were calculated for adult worker by Eqs. (1), (5), (6), (7). The basic parameters for calculating cancer risk of exposure are shown in Table S5 (in SM), and other calculation parameters are the same as those for the residential exposure as shown in Tables S6, S7 and S8. The calculated results are summarized in Tables S11 and S12 and Fig. 6. For PAHs, there were 3 sites (9.7\%) with cancer values higher than $1 \times 10^{-6}$. The maximum TLCR value was $4.10 \times 10^{-6}$ with the mean at $3.37 \times 10^{-7}$, which indicated that the PAH pollution for occupational exposure was at a safe level. For $\sum$ OCPs, the maximum TLCR value was $1.10 \times 10^{-6}$ and the mean was $1.45 \times 10^{-7}$, while only $2(6.5 \%)$ sites had values slightly higher than $1 \times 10^{-6}$, which suggested that the OCP pollution was at a low level. For $\sum$ PCBs, the TLCR results were all lower than $1 \times 10^{-6}$, and the maximum TLCR value was $5.35 \times 10^{-7}$ with a mean of $6.55 \times 10^{-8}$, which showed that there was of no cancer risk from PCB contaminant for occupational workers in the study area.

For TEQ concentrations of PAHs, the parameters and the calculated results are shown in Table S22 (in SM). In this study, the total toxic concentrations of 16 PAHs were in the range of $0.03-867.05 \mathrm{ng} / \mathrm{g}-\mathrm{BaP}$ eq with a mean of $71.95 \mathrm{ng} / \mathrm{g}-\mathrm{BaP}_{\mathrm{eq}}$. The total $\mathrm{BaP}_{\mathrm{eq}}$ of seven carcinogenic PAHs was approximate to that of 16 PAHs (Table S22 in SM), suggesting that these 7 carcinogenic PAHs contributed most to the TEQ in the topsoil samples. The contributions of different PAHs to the TEQ decreased in the order: $\mathrm{BaP}(62.5 \%)>\mathrm{DBA}(19.2 \%)>\mathrm{BbF}(6.2 \%)>\mathrm{BaA}$ $(4.3 \%)>\operatorname{InP}(3.1 \%)>\operatorname{BkF}$ (1.6\%). The TEQ concentrations were significantly lower than those in soils at a semi-dried area of India (Masih and Taneja, 2006), and also lower than those of agricultural area in Delhi and Shanghai (Agarwal et al., 2009; Jiang et al., 2011a); but higher than those in the soil from unpolluted areas of Spain (Nadal et al., 2004).

For TEQ concentrations of PCBs, the parameters and the calculated results are shown in Table S23 (in SM). The total toxic concentrations of PCBs in soil samples ranging from $0-55.66 \mathrm{pg} / \mathrm{g}-\mathrm{WHO}_{2005}$ with a mean of $3.93 \mathrm{pg} / \mathrm{g}-\mathrm{WHO}_{2005}$, were lower than those of PAHs in the study as discuss above. The contributions of 4 dioxin-like PCBs to the TEQ decreased in the order: 118-CB $(56.5 \%)>81-\mathrm{CB}(49.9 \%)>105-\mathrm{CB}$ $(12.2 \%)>157-\mathrm{CB}(6.6 \%)$. The TEQ concentrations in the study were significantly lower than those in soils at less industrial area of India (Devi et al., 2014; Kumar et al., 2011) and urban area in Moscow and in Dalian (Agapkina et al., 2011; Wang et al., 2008), but higher than those reported in Slovakia (Dömötörová et al., 2012).

\subsubsection{Non-carcinogenic risks}

For residential PAH exposure, the HQ calculation parameters are shown in Tables S5 and S13 (in SM), and the results of children noncancer exposure risks are summarized in Tables S16 and S17 (in SM).

The children non-cancer risks of THQ values for PAHs in all sampling sites were significantly lower than the safety level (THQ $<1$ ). The maximum THQ of $6 \mathrm{PAHs}$ was $1.06 \times 10^{-2}$, with the mean at
$1.3 \times 10^{-3}$, indicating than there were no non-carcinogenic risks of PAH pollution for children in the residential area. For OCPs and PCBs, the HQ of children exposure calculation method was the same as that for PAHs, and the parameters are shown in Tables S5, S14 and S15. The results of the calculations are summarized in Tables S16 and S17 (in SM). The THQ of OCPs and PCBs in all sampling sites for residential children exposure was lower than 1. The maximum THQ of OCPs and PCBs was 0.115 and 0.11 , with the mean at $1.15 \times 10^{-2}$ and $1.35 \times 10^{-2}$, respectively. These results indicated that these pollutants did not pose hazard to children target groups.

For adult, the calculation parameters for HQ of PAHs are shown in Tables S5 and S13, and the results are listed in Tables S18 and S19 (in SM). The THQ of PAHs for adult was lower than 1 in all sites, and the maximum THQ of PAHs was $3.07 \times 10^{-4}$, with the mean at $2.92 \times 10^{-5}$, which suggested that there were no non-cancer risks of $\mathrm{PAH}$ pollution for adult in the residential area. For OCPs and PCBs, the HQ for adult exposure equation was the same as that for PAHs and the calculation parameters are listed in Tables S5, S14 and S15. The calculation results are shown in Tables S18 and S19 (in SM). The maximum THQ of OCPs and PCBs was $1.28 \times 10^{-2}$ and $1.32 \times 10^{-2}$, with the mean at $1.32 \times 10^{-3}$ and $1.62 \times 10^{-3}$, respectively. In all sites, the THQ of OCPs and PCBs was less than 1 for residential adult exposure, indicating that these pollutants did not pose non-cancer risks to target groups.

For occupational POP exposure, the basic parameters for calculating risk of HQ exposure are listed in Table S5, and other calculation parameters are the same as residential shown in Tables S13, S14 and S15. The results are summarized in Tables S20 and S21 (in SM). The THQ of PAHs, OCPs and PCBs exposure for workers was far below the safety value $(<1)$ in all sampling sites with the maximum value at $2.19 \times 10^{-3}$, $9.78 \times 10^{-3}$ and $1.16 \times 10^{-2}$, respectively, which indicated that adult target population can work in the study area without the non-cancer risks due to POPs exposure.

\section{Conclusions}

The concentrations of POPs in the topsoils of Beijing Yanshan petrochemical area were analyzed systematically. The concentration of $\sum$ PAHs ranged from 35.29 to $6120.22 \mathrm{ng} / \mathrm{g}$ with the mean concentration at $906.11 \mathrm{ng} / \mathrm{g}$, $\sum$ OCPs varied from 4.13 to $7215.24 \mathrm{ng} / \mathrm{g}$ with a mean of $336.13 \mathrm{ng} / \mathrm{g}$, and $\sum$ PCBs ranged from 2.21 to $4008.47 \mathrm{ng} / \mathrm{g}$ with a mean of $486.12 \mathrm{ng} / \mathrm{g}$. Multivariate statistical analyses and the diagnostic ratios suggested that the PAHs predominantly originated from the local emission from fuel combustion in the study area. The main source of DDTs was the recent input of dicofol, while the HCHs in the topsoils were due to the recent input of lindane. The commercial products Aroclor 1016, 1242 and 1248 were responsible for the PCBs, in which the tri-CBs, tetra-CBs and penta-CBs were the dominant components. The results of risk assessments showed that residential lifetime exposure to PAHs carried higher cancer risks than exposure to OCPs and PCBs. Nevertheless, most of the calculated risk values for POPs were below $1 \times 10^{-5}$, which indicated an acceptable risk level or a virtually safe level for target groups. Several sites around the Dongfeng chemical plant which possessed risk values higher than $1 \times 10^{-6}$, should be paid attention to. For an occupational worker, the cancer risks of POPs exposure in most sites were less than $1 \times 10^{-6}$. In all sampling sites, HQs of PAHs, OCPs and PCBs for three target group exposure were all below 1 , which suggested that the pollutants did not pose non-cancer hazard to the target groups.

\section{Acknowledgments}

This research was financially supported by the Fundamental Research Funds for the Central Universities (2652014003) and State Key Laboratory of Biogeology and Environmental Geology (GBL201405). 


\section{References}

Agapkina, G.I., Efimenko, E.S., Brodskiy, E.S., Shelepchikov, A.A., Feshin, D.B., 2011. Concentration and distribution of polychlorinated biphenyls in soils of Moscow. Mosc. Univ. Soil Sci. Bull. 66, 36-41.

Agarwal, T., Khillare, P.S., Shridhar, V., Ray, S., 2009. Pattern, sources and toxic potential of PAHs in the agricultural soils of Delhi, India. J. Hazard. Mater. 163, 1033-1039.

Ahlborg, U.G., Becking, G.C., Birnbaum, L.S., Brouwer, A., Derks, H.J.G.M., Feeley, M., Gor, G., Hanberg, A., Larsen, J.C., Liem, A.K.D., Safe, S.H., Schlatter, C., Waern, F., Younes, M., Yrjanheikki, E., 1994. Toxic equivalency factors for dioxin-like PCB: Report on WHO-ECEH and IPCS consultation, December 1993. Chemosphere 28 (6), 1049-1067.

Albanese, S., Fontaine, B., Chen, W., Lima, A., Cannatelli, C., Piccolo, A., Qi, S.H., Wang, M.H., De Vivo, B., 2015. Polycyclic aromatic hydrocarbons in the soils of a densely populated region and associated human health risks: the Campania Plain (Southern Italy) case study. Environ. Geochem. Health 37 (1), 1-20.

Cachada, A., Lopes, L.V., Hursthouse, A.S., Biasioli, M., Grčman, H., Otabbong, E., Davidson, C.M., Duartea, A.C., 2009. The variability of polychlorinated biphenyls levels in urban soils from five European cities. Environ. Pollut. 157, 511-518.

Cachada, A., Pato, P., Rocha-Santos, T., Ferreira da Silva, E., Duarte, A.C., 2012. Levels, sources and potential human health risks of organic pollutants in urban soils. Sci. Total Environ. 430, 184-192.

Capuano, F., Cavalchi, B., Martinelli, G., Pecchini, G., Renna, E., Scaroni, I., Bertacchi, M., Bigliardi, G., 2005. Environmental prospection for PCDD/PCDF, PAH, PCB and heavy metals around the incinerator power plant of Reggio Emilia town (Northern Italy) and surrounding main roads. Chemosphere 58, 1563-1569.

CCME (Canadian Council of Ministers of the Environment), 2007. Canadian Soil Quality Guidelines for Protection of Environmental and Human Health. http://www.ccme. ca/files/Resources/supporting_scientific_documents/pah_soqg_ssd_1401.pdf.

Cheng, H.X., Li, X.H., Wang, Y.P., Zhao, C.D., Liu, Y.H., Chen, H.H., Xu, X.B., 2011. Profile of organochlorine pesticides in soil cores from some hotspot areas of Beijing, China. Bull. Environ. Contam. Toxicol. 87, 175-179.

Cornejo, J., Hermosın, M.C., Celis, R., Cox, L., 2005. Methods to determine sorption of pesticides and other organic compounds. In: Alvarez-Benedi, J., Munoz-Carpena, R. (Eds.), Soil-Water-Solute Process Characterization: An Integrated Approach. CRC Press, Boca Raton, FL, USA, pp. 435-464.

Devi, N.L., Yadav, I.C., Qi, S.H., Chakraborty, P., Dan, Y., 2014. Distribution and risk assessment of polychlorinated biphenyls (PCBs) in the remote air and soil of Manipur India. Manipur Environ. Earth Sci. 72, 3955-3967.

Dobbins, R.A., Fletcher, R.A., Benner Jr., B.A., Hoeft, S., 2006. Polycyclic aromatic hydrocarbons in flames, in diesel fuels, and in diesel emissions. Combust. Flame 144, 773-781.

Dömötörová, M., Sejáková, Z.S., Kočan, A., Čonka, K., Chovancová, J., Fabišiková, A., 2012. PCDDs, PCDFs, dioxin-like PCBs and indicator PCBs in soil from five selected areas in Slovakia. Chemosphere 89, 480-485.

Dragan, D., Cucu-Man, S., Dirtu, A.C., Mocanu, R., Vaeck, L.V., Covaci, A., 2006. Occurrence of organochlorine pesticides and polychlorinated biphenyls in soils and sediments from Eastern Romania. Int. J. Environ. Anal. Chem. 86, 833-842.

Duval, M.M., Friedlander, S.K., 1981. Source resolution of polycyclic aromatic hydrocarbons in Los Angeles atmosphere-application of CMB with first order decay. USEPA Report no EPA-600/2-81-161.

Fu, S., Li, K., Yang, Z.Z., Xu, X.B., 2008a. Composition, distribution, and characterization of organochlorine pesticides in sandstorm deposition in Beijing, China. Water Air Soil Pollut. 193, 343-352.

Fu, S., Yang, Z.Z., Li, K., Xu, X.B., 2008b. Polychlorinated biphenyl residues in sandstorm deposition in Beijing, China. Chemosphere 73, 962-966.

Fu, S., Cheng, H.X., Liu, Y.H., Xia, X.J., Xu, X.B., 2009a. Composition, distribution and characterization of polycyclic aromatic hydrocarbons in soil in Linfen, China. Bull. Environ. Contam. Toxicol. 85, 15-21.

Fu, S., Cheng, H.X., Liu, Y.H., Yang, Z.Z., Xu, X.B., 2009b. Spatial character of polychlorinated biphenyls from soil and respirable particulate matter in Taiyuan, China. Chemosphere $74,1477-1484$.

Guo, H., Lee, S.C., Ho, K.F., Wang, X.M., Zou, S.C., 2003. Particle-associated polycyclic aromatic hydrocarbons in urban air of Hong Kong Atmos. Environ. 37, 5307-5317.

Harrison, R.M., Smith, D.J.T., Luhana, L., 1996. Source apportionment of atmospheric polycyclic aromatic hydrocarbons collected from an urban location in Birmingham, UK. Environ. Sci. Technol. 30, 825-832.

Hassanin, A., Lee, R.G.M., Steinnes, E., Jones, K.C., 2005. PCDD/Fs in Norwegian and UK soils: implications for sources and environmental cycling. Environ. Sci. Technol. 39, 4784-4792.

Health Canada, 2010. Federal contaminated site risk assessment in Canada. Part I: guidance on human health preliminary quantitative risk assessment (PQRA). Version 2.0. Health Canada, Ottawa, ON

Jiang, Y.F., Wang, X.T., Wang, F., Jia, Y., Wu, M.H., Sheng, G.Y., Fu, J.M., 2009. Levels, composition profiles and sources of polycyclic aromatic hydrocarbons in urban soil of Shanghai, China. Chemosphere 75, 1112-1118.

Jiang, Y.F., Wang, X.T., Wu, M.H., Sheng, G.Y., Fu, J.M., 2011a. Contamination, source identification, and risk assessment of polycyclic aromatic hydrocarbons in agricultural soil of Shanghai, China. Environ. Monit. Assess. 183, 139-150.

Jiang, Y.F., Wang, X.T., Zhu, K., Wu, M.H., Sheng, G.Y., Fu, J.M., 2011b. Polychlorinated biphenyls contamination in urban soil of Shanghai: level, compositional profiles and source identification. Chemosphere 83, 767-773.

Jiao, W., Wang, T., Khim, J.S., Luo, W., Hu, W., Naile, J.E., Giesy, J.P., Lu, Y., 2012. PAH in surface sediments from coastal and estuarine areas of the northern Baohai and Yellow Seas, China. Environ. Geochem. Health 34, 445-456.

Jones, K.C., De Voogt, P., 1999. Persistent organic pollutants (POPs): state of the science. Environ. Pollut. 100, 209-221.
Kaisarevic, S., Andric, N., Bobic, S., Trickovic, J., Teodorovic, I., Vojinovic-Miloradov, M. Kovacevic, R.Z., 2007. Detection of dioxin-like contaminants in soil from the area of oil refineries in Vojvodina region of Serbia. Bull. Environ. Contam. Toxicol. 79, 422-426.

Kaisarevic, S., Hilscherova, K., Weber, R., Sundqvist, K.L., Tysklind, M., Voncina, E., Bobic, S. Andric, N., Pogrmic-Majkic, K., Vojinovic-Miloradov, M., Giesy, J.P., Kovacevic, R. 2011. Characterization of dioxin-like contamination in soil and sediments from the "hot spot" area of petrochemical plant in Pancevo (Serbia). Environ. Sci. Pollut. Res. $18,677-686$.

Kalf, D.F., Crommentuijn, T., Van de Plassche, E.J., 1997. Environmental quality objectives for 10 polycyclic aromatic hydrocarbons. Ecotoxicol. Environ. Saf. 36, 89-97.

Kumar, B., Kumar, S., Goel, G., Gaur, R., Mishra, M., Singh, S.K., Prakash, D., Chakraborty, P., Sharma, C.S., 2011. Distribution of polychlorinated biphenyls in agricultural soils from NCR, Delhi, India. Ann. Biol. Res. 2, 247-254.

Li, C.K., Kamens, R.M., 1993. The use of polycyclic aromatic hydrocarbons as source signatures in receptor modeling. Atmos. Environ. 27A, 523-532.

Li, Y.F., Cai, D.G., Shan, Z.J., Zhu, Z.L., 2001. Gridded usage inventories of technical hexachlorocyclohexane and lindane for China with $1 / 6^{\circ}$ latitude by $1 / 4^{\circ}$ longitude resolution. Arch. Environ. Contam. Toxicol. 41, 261-266.

Li, X.H., Ma, L.L., Liu, X.F., Fu, S., Cheng, H.X., Xu, X.B., 2005. Distribution of organochlorine pesticides in urban soil from Beijing, People's Republic of China. Bull. Environ. Contam. Toxicol. 74 (5), 938-945.

Li, X.H., Ma, L.L., Liu, X.F., Fu, S., Cheng, H.X., Xu, X.B., 2006. Polycyclic aromatic hydrocarbon in urban soil from Beijing, China. J. Environ. Sci. (China) 18, 944-950.

Li, X.H., Wang, W., Wang, J., Cao, X.L., Wang, X.F., Liu, J.C., Liu, X.F., Xu, X.B., Jiang, X.N., 2008. Contamination of soils with organochlorine pesticides in urban parks in Beijing China. Chemosphere 70, 1660-1668.

Li, J., Lu, Y., Shi, Y., Wang, T.Y., Wang, G., Luo, W., Jiao, W.T., Chen, C.L., Yan, F., 2011. Environmental pollution by persistent toxic substances and health risk in an industrial area of China. J. Environ. Sci. (China) 23, 1359-1367.

Li, C., Zheng, M.H., Zhang, B., Gao, L.R., Liu, L.D., Jiang, X.X., Liu, Z.T., 2012. Levels of PCDD/ Fs, Di-PCBs and HCB in air, soils and sediments from a city with multiple thermalrelated industries in China. Bull. Environ. Contam. Toxicol. 89, 542-546.

Lin, T., Hu, L., Shi, X.F., Li, Y.Y., Guo, Z.G., Zhang, G., 2012. Distribution and sources of organochlorine pesticides in sediments of the coastal East China Sea. Mar. Pollut. Bull. 64 1549-1555.

Liu, S.D., Xia, X.H., Yang, L.Y., Shen, M.H., Liu, R.M., 2010. Polycyclic aromatic hydrocarbons in urban soils of different land uses in Beijing, China: distribution, sources and thei correlation with the city's urbanization history. J. Hazard. Mater. 177, 1085-1092.

Ma, J., Zhou, Y.Z., 2011. Soil pollution by polycyclic aromatic hydrocarbons: a comparison of two Chinese cities. J. Hazard. Mater. 23, 1518-1523.

Marr, L.C., Kirchstetter, T.W., Harley, R.A., Miguel, A.H., Hering, S.V., Hammond, S.K., 1999. Characterization of polycyclic aromatic hydrocarbons in motor vehicle fuels and exhaust emissions. Environ. Sci. Technol. 33 (18), 3091-3099.

Masih, A., Taneja, A., 2006. Polycyclic aromatic hydrocarbons concentrations and related carcinogenic potencies in soil at a semi-arid region of India. Chemosphere 65, 449-456.

Mastral, A.M., Callen, M., Murillo, R., 1996. Assessment of PAH emissions as a function of coal combustion variables. Fuel 75, 1533-1536.

Meijer, S.N., Steinnes, E., Ockenden, W.A., Jones, K.C., 2002. Influence of environmenta variables on the spatial distribution of PCBs in Norwegian and UK soils: implications for global cycling. Environ. Sci. Technol. 36, 2146-2153.

Meijer, S.N., Ockenden, W.A., Steinnes, E., Corrigan, B.P., Jones, K.C., 2003a. Spatial and temporal trends of POPs in Norwegian and UK background air: implications for global cycling. Environ. Sci. Technol. 37, 454-461.

Meijer, S.N., Shoeib, M., Jones, K.C., Harner, T., 2003b. Air-soil exchange of organochlorine pesticides in agricultural soils. 2. Laboratory measurements of the soil-air partition coefficient. Environ. Sci. Technol. 37, 1300-1305.

Ministry of Environmental Protection of the People's Republic of China, 1995. Environmental Quality Standard for Soils. http://kjs.mep.gov.cn/hjbhbz/bzwb/trhj/trhjzlbz/ 199603/t19960301 82028.htm.

Motelay-Massei, A., Ollivon, D., Garban, B., Teil, M.J., Blanchard, M., Chevreuil, M., 2004 Distribution and spatial trends of PAHs and PCBs in soils in the Seine River basin, France. Chemosphere 55, 555-565.

Nadal, M., Schuhmacher, M., Domingo, J.L., 2004. Levels of PAHs in soil and vegetation samples from Tarragona County, Spain. Environ. Pollut. 132, 1-11.

Nadal, M., Schuhmacher, M., Domingo, J.L., 2007. Levels of metals, PCBs, PCNs and PAHs in soils of a highly industrialized chemical/petrochemical area: temporal trend. Chemosphere 66, 267-276.

Nadal, M., Shuhmacher, M., Domingo, J.L., 2011. Long-term environmental monitoring of persistent organic pollutants and metals in a chemical/petrochemical area: human health risks. Environ. Pollut. 159, 1769-1777.

Peng, C., Chen, W.P., Liao, X.L., Wang, M.E., Ouyang, Z.Y., Jiao, W.T., Bai, Y., 2011. Polycyclic aromatic hydrocarbons in urban soils of Beijing: status, sources, distribution and potential risk. Environ. Pollut. 159, 802-808.

Peng, C., Ouyang, Z.Y., Wang, M., Chen, W., Jiao, W., 2012. Vegetative cover and PAHs accumulation in soils of urban green space. Environ. Pollut. 161, 36-42.

Qiu, X., Zhu, T., Yao, B., Hu, J., Hu, S., 2005. Contribution of dicofol to the current DDT pollution in China. Environ. Sci. Technol. 39, 4385-4390.

Ren, N.Q., Que, M.X., Li, Y.F., Liu, Y., Wan, X.N., Xu, D.D., Sverko, E., Ma, J.M., 2007. Polychlorinated biphenyls in Chinese surface soils. Environ. Sci. Technol. 41, 3871-3876.

Rovira, J., Mari, M., Nadal, M., Schuhmacher, M., Domingo, J.L., 2010. Environmental monitoring of metals, PCDD/Fs and PCBs as a complementary tool of biological surveillance to assess human health risks. Chemosphere 80, 1183-1189.

Shi, Y., Meng, F., Guo, F., Lu, Y., Wang, T., Zhang, H., 2005. Residues of organic chlorinated pesticides in agricultural soils of Beijing, China. Arch. Environ. Contam. Toxicol. 49, 37-44. 
Shi, Y.J., Lu, Y.L., Wang, T.Y., Wang, G., Luo, W., 2009. Comparison of organochlorine pesticides occurrence, origin, and character in agricultural and industrial soils in Beijing. Arch. Environ. Contam. Toxicol. 57 (3), 447-455.

Syed, J.H., Malik, R.N., 2011. Occurrence and source identification of organochlorine pesticides in the surrounding surface soils of the Ittehad chemical industries KalaShah Kaku, Pakistan. Environ. Earth Sci. 62, 1311-1321.

Tang, L., Tang, X.Y., Zhu, Y.G., Zheng, M.H., Miao, Q.L., 2005. Contamination of polycyclic aromatic hydrocarbons (PAHs) in urban soils in Beijing, China. Environ. Int. 31, $822-828$.

Undeman, E., Fischer, S., McLachlan, M.S., 2011. Evaluation of a novel high throughput screening tool for relative emissions of industrial chemicals used in chemical products. Chemosphere 82, 996-1001.

UNEP, 2001. Stockholm Convention on Persistent Organic Pollutants (POPs), Interim Secretariat for the Stockholm Convention. United Nations Environmental Programme (UNEP) Chemicals, Geneva, Switzerland (October 2001. <http://www.pops.int>).

USEPA, 1991. Risk assessment guidance for superfund (RAGS), volume I: human health evaluation manual. Part B, Development of Risk-based Preliminary Remediation Goalsoffice of research and development, Washington DC (EPA/540/R-92/003 publication 92857-01B RAGS).

USEPA, 2013. Regional Screening Levels (RSL) for chemical contaminants at superfund sites. (RSL Soil Table May 2013) Regional Screening Table User's Guide.

Van den Berg. M., Birnbaum, L.S., Denison, M., De Vito, M., Farland, W., Feeley, M., et al., 2006. The 2005 World Health Organization re-evaluation of human and mammalian toxic equivalency factors for dioxins and dioxin-like compounds. Toxicol. Sci. 93, 223-241.

VROM, 2009. Ministry of Housing, Spatial Planning and Environment DirectoratesGeneral for Environment Protection, Department of Soil Protection, Netherlands. Circular on Target Values and Intervention Values for Soil Remediation.

Wang. D.G. Yang M. Jia, H.L, Zhou, L, Li, Y.F, 2008. Levels, distributions and profiles of polychlorinated biphenyls in surface soils of Dalian, China. Chemosphere 73, 38-42.

Wang, G., Lu, Y.L., Wang, T.Y., Zhang, X., Han, J.Y., Luo, W., Shi, Y.J., Li, J., Jiao, W.T., 2009a. Factors influencing the spatial distribution of organochlorine pesticides in soils surrounding chemical industrial parks. J. Environ. Qual. 38, 180-187.

Wang, K.Y., Shen, Y.T., Zhang, S.C., Ye, Y.B., Shen, Q., Hu, J.D., Wang, X.J., 2009b. Application of spatial analysis and multivariate analysis techniques in distribution and source study of polycyclic aromatic hydrocarbons in the topsoil of Beijing, China. Environ. Geol. 56, 1041-1050.
Wang, W.T., Massey Simonich, S.L., Xue, M., Zhao, J.Y., Zhang, N., Wang, R., Cao, J., Tao, S., 2010. Concentrations, sources and spatial distribution of polycyclic aromatic hydrocarbons in soils from Beijing, Tianjin and surrounding areas, North China. Environ. Pollut. 158 (5), 1245-1251.

Wang, W., Huang, M.J., Kang, Y., Wang, H.S., Leung, A.O.W., Cheung, K.C., Wong, M.H., 2011a. Polycyclic aromatic hydrocarbons (PAHs) in urban surface dust of Guangzhou, China: status, sources and human health risk assessment. Sci. Total Environ. 409, 4519-4527.

Wang, W.T., Massey Simonich, S.M., Giri, B., Xue, M., Zhao, J.Y., Chen, S.J., Shen, H.Z., Shen, G.F., Wang, R., Cao, J., Tao, S., 2011b. Spatial distribution and seasonal variation of atmospheric bulk deposition of polycyclic aromatic hydrocarbons in Beijing-Tianjing region, North China. Environ. Pollut. 159, 287-293.

Wu, S., Xia, X., Yang, L., Liu, H., 2011. Distribution, source and risk assessment of polychlorinated biphenyls (PCBs) in urban soils of Beijing, China. Chemosphere 82, 732-738.

Yang, W.R., Wang, R.S., Zhou, C.B., Li, F., 2009. Distribution and health assessment of organochlorine pesticides (OCPs) in industrial site soils: a case study of urban renewal in Beijing, China. J. Environ. Sci. (China) 21, 366-372.

Yang, L.Y., Xia, X.H., Liu, S.D., Bu, Q.W., 2010. Distribution and sources of DDTs in urban soils with six types of land use in Beijing, China. J. Hazard. Mater. 174, 100-107.

Yang, L., Xia, X., Hu, L., 2012. Distribution and health risk assessment of HCHs in urban soil of Beijing, China. Environ. Monit. Assess. 184, 2377-2387.

Yuan, G.L., Wu, H.Z., Fu, S., Han, P., Lang, X.X., 2014. Persistent organic pollutants (POPs) in the topsoil of typical urban renewal area in Beijing, China: status, sources and potential risk. J. Geochem. Explor. 138, 94-103.

Yunker, M.B., Macdonald, R.W., Vingarzan, R., Mitchell, R.H., Goyette, D., Sylvestre, S., 2002. PAHs in the Fraser River basin: a critical appraisal of PAH ratios as indicators of PAH source and composition. Org. Geochem. 33, 489-515.

Zhang, Z.L., Huang, J., Yu, G., Hong, H.S., 2004. Occurrence of PAHs, PCBs and organochlorine pesticides in Tonghui River of Beijing, China. Environ. Pollut. 130, 249-260.

Zhang, Y.X., Schauer, J.J., Zhang, Y.H., Zeng, L.M., Wei, Y.J., Liu, Y., Shao, M., 2008. Characteristics of particulate carbon emissions from real-world Chinese coal combustion. Environ. Sci. Technol. 42, 5068-5073.

Zheng, X.Y., Liu, X.D., Liu, W.J., Jiang, G.B., Yang, R.Q., 2009. Concentrations and source identification of organochlorine pesticides (OCPs) in soils from Wolong Natural Reserve. China Sci. Bull. 54 (5), 743-751. 